\title{
Effects of GLP-1R agonist or co-cyprindiol, in combination with metformin, on polycystic ovary syndrome in overweight women: A Randomized Clinical Trial
} \author{
1 , and Min Long ${ }^{5}$ \\ ${ }^{1}$ Third Military Medical University Second Affiliated Hospital \\ ${ }^{2}$ Medical School of Nanjing University \\ ${ }^{3}$ Chinese Academy of Sciences \\ ${ }^{4}$ Baylor College of Medicine \\ ${ }^{5}$ Affiliation not available
}

Mingyu Liao ${ }^{1}$, Xing $\mathrm{Li}^{2}$, Hao Zhang ${ }^{3}$, Ling Zhou ${ }^{1}$, Liu Shi ${ }^{1}$, Weixin Li $^{1}$, Rufei Shen ${ }^{1}$, Guiliang Peng ${ }^{1}$, Huan Zhao ${ }^{1}$, Jiaqing Shao ${ }^{2}$, Xiujie $\mathrm{Wang}^{3}$, Zheng Sun ${ }^{4}$, Hongting Zheng

October 31, 2021

\begin{abstract}
Objective:Polycystic ovary syndrome (PCOS) is characterized by reproductive dysfunctions and metabolic disorders. This study aims to compare the therapeutic effectiveness of glucagon-like peptide-1 receptor agonist (GLP-1RA) + Metformin (Met) versus co-cyprindiol (cyproterone acetate/ethinylestradiol, CPA/EE) + Met in overweight PCOS women and identify potential biomarkers. Methods: In this prospective, open-label randomized controlled trial, we recruited 60 overweight PCOS women into two groups at a 1:1 ratio to receive CPA/EE $(2 \mathrm{mg} /$ day $)+\operatorname{Met}(1,500 \mathrm{mg} /$ day) or GLP-1RA (liraglutide, 0.6-1.2 mg/day) + Met $(1,500 \mathrm{mg} /$ day $)$ for 12 weeks. The clinical effectiveness and adverse effects were evaluated, followed by plasma proteomic analysis and verification of critical biomarkers by ELISA. Results: Both interventions improved menstrual cycle, polycystic ovaries, LH levels, and LH/FSH ratio; meanwhile reduced the body weight, BMI, HbA1c, FBG, OGTT-30 min insulin, IL-6 and TNF- $\alpha$. Whereas, GLP-1RA + Met showed a more robust improvement on HbA1c, HOMA-IR, lipid profiles, inflammatory parameters, and ovulation. CPA/EE + Met was more effective in reducing hyperandrogenemia. Plasma proteomic analysis revealed that the interventions altered proteins involved in reactive oxygen species detoxification (PRDX6, GSTO1, GSTP1, GSTM2), platelet degranulation (FN1), and the immune response (SERPINB9). Conclusions: CPA/EE+Met or GLP-1RA + Met treatment improved reproductive functions and alleviated metabolic disorders in overweight PCOS women. GLP-1RA + Met had a superior improvement in metabolism and inflammation. The novel plasma biomarkers PRDX6, FN1, and SERPINB9, might be indicators and targets for PCOS treatment.
\end{abstract}

\section{Hosted file}

manuscript.docx available at https://authorea.com/users/443875/articles/543773-effectsof-glp-1r-agonist-or-co-cyprindiol-in-combination-with-metformin-on-polycystic-ovarysyndrome-in-overweight-women-a-randomized-clinical-trial

\section{Hosted file}

Table.docx available at https://authorea.com/users/443875/articles/543773-effects-of-glp-1ragonist-or-co-cyprindiol-in-combination-with-metformin-on-polycystic-ovary-syndrome-inoverweight-women-a-randomized-clinical-trial 


\section{Hosted file}

Supplementary Table.docx available at https://authorea.com/users/443875/articles/543773effects-of-glp-1r-agonist-or-co-cyprindiol-in-combination-with-metformin-on-polycysticovary-syndrome-in-overweight-women-a-randomized-clinical-trial

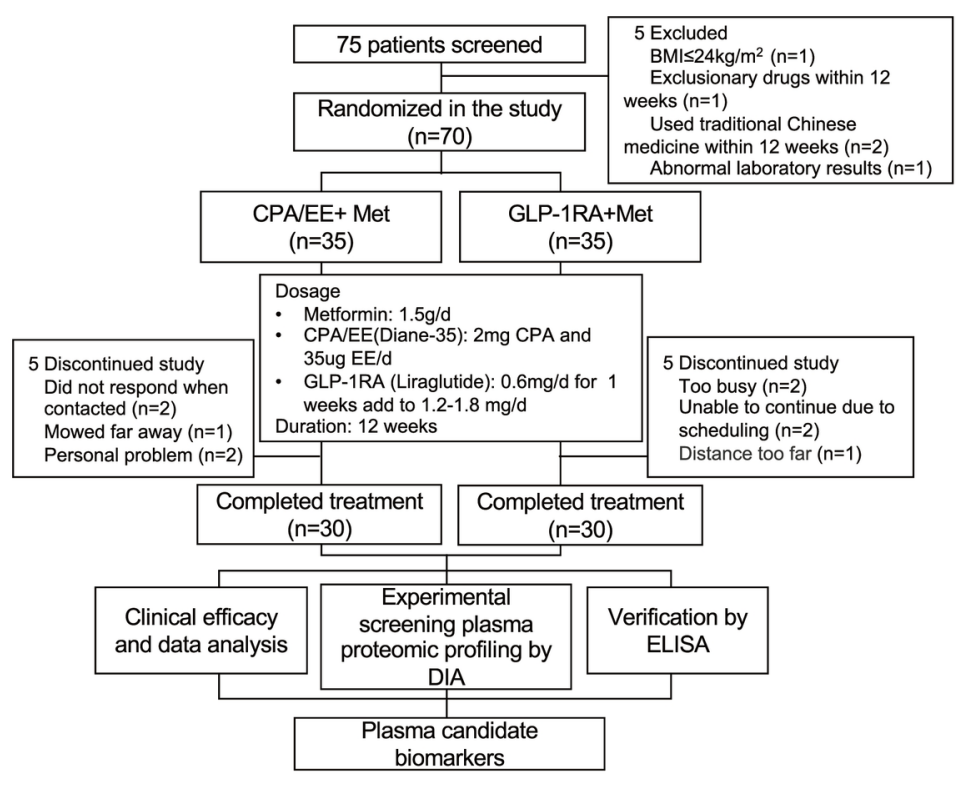



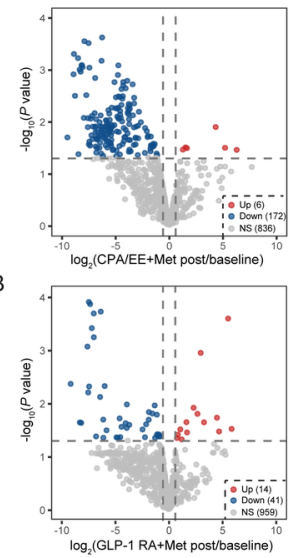

D

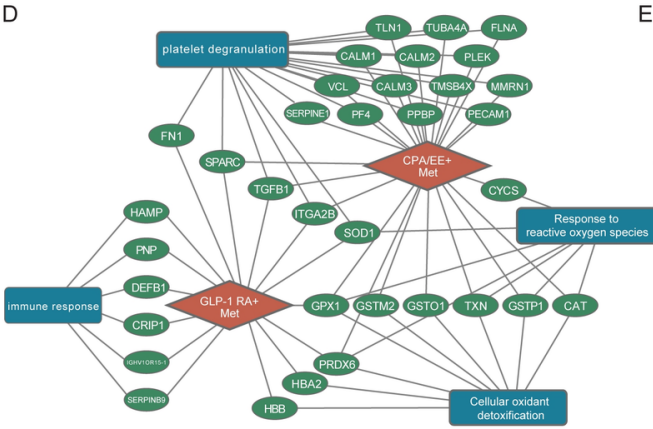

E
C
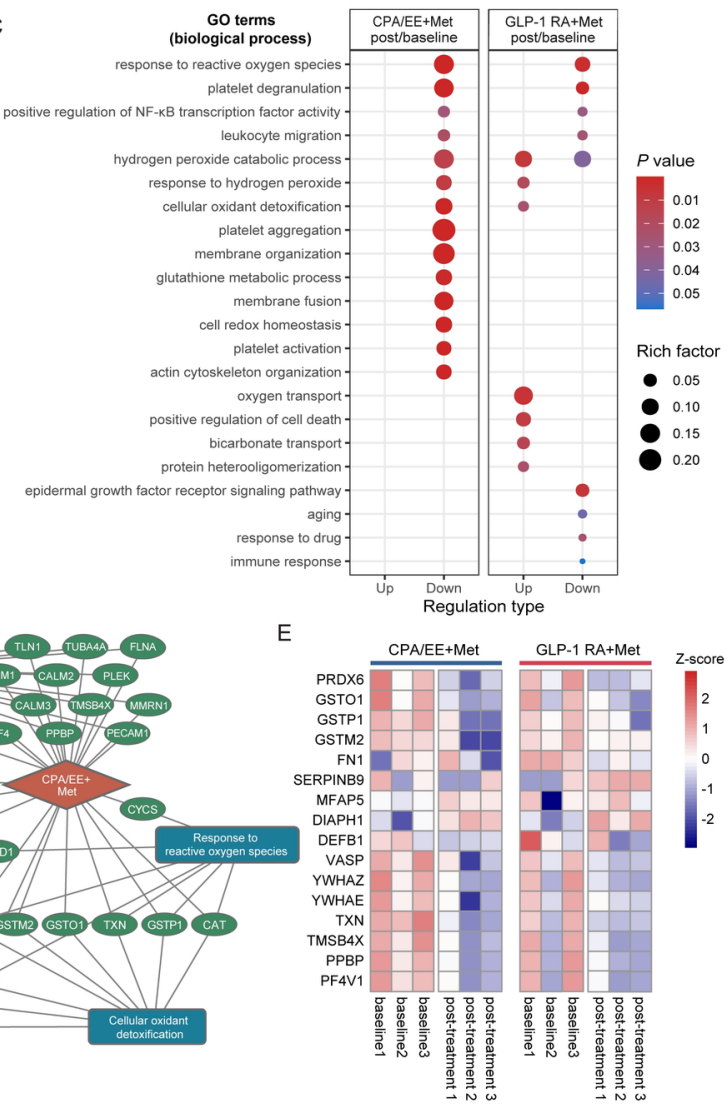
A

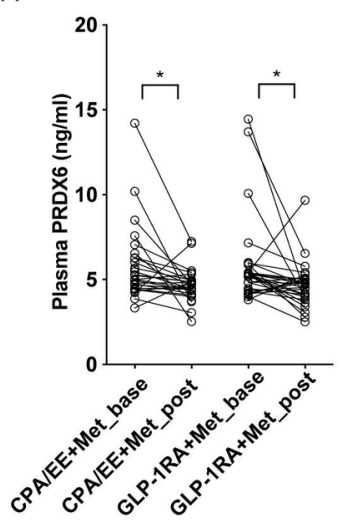

D

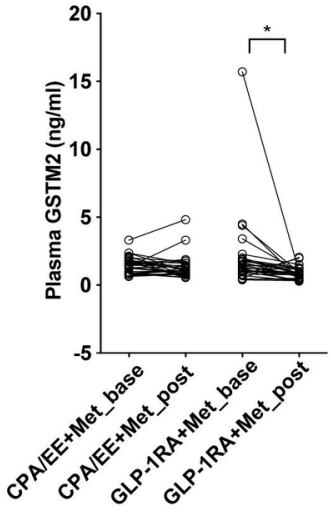

B

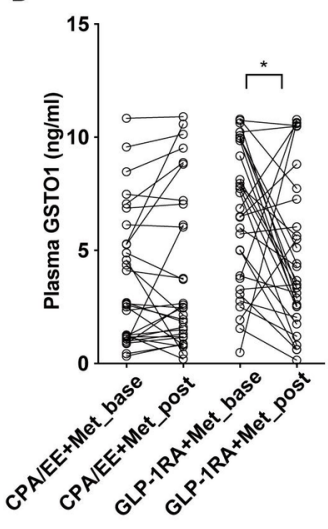

E

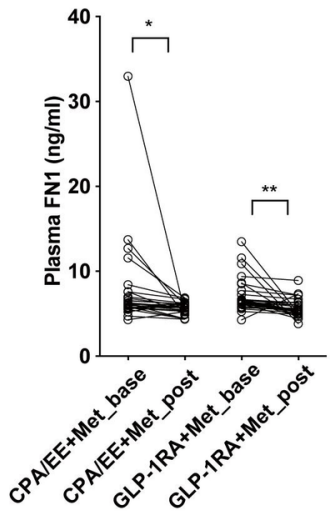

C

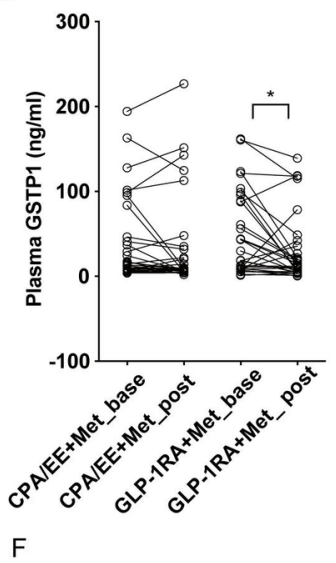

F

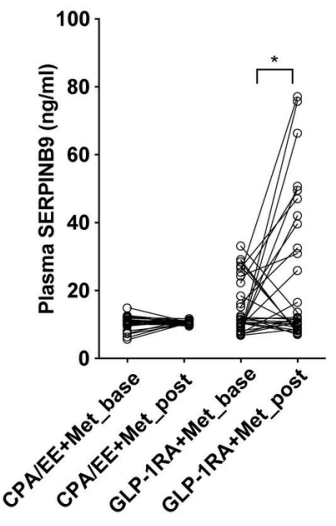



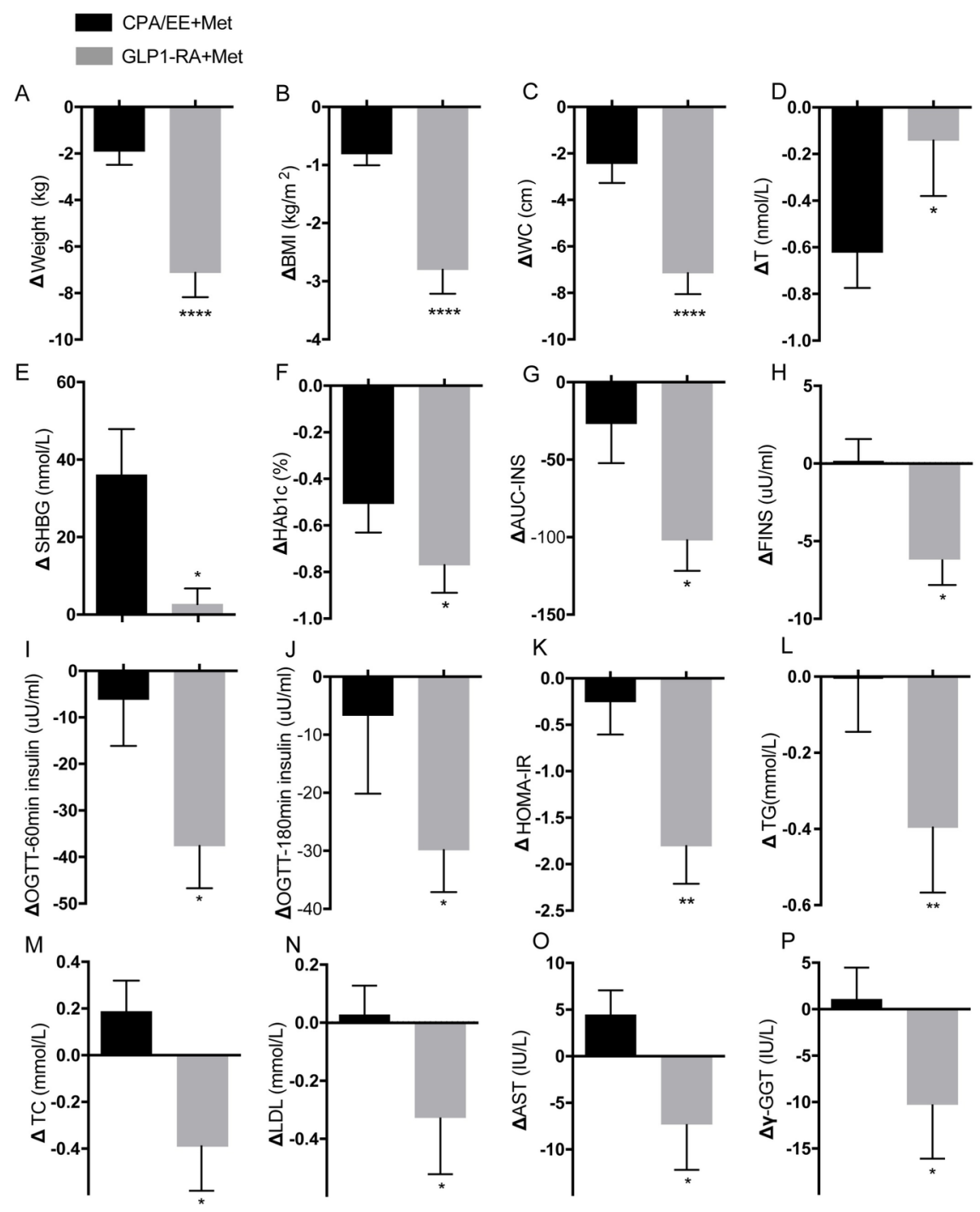


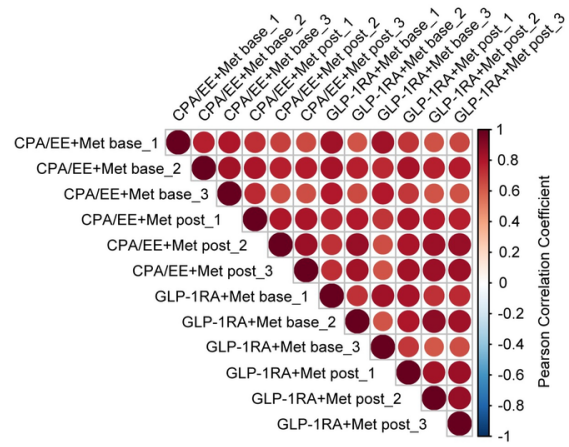

B

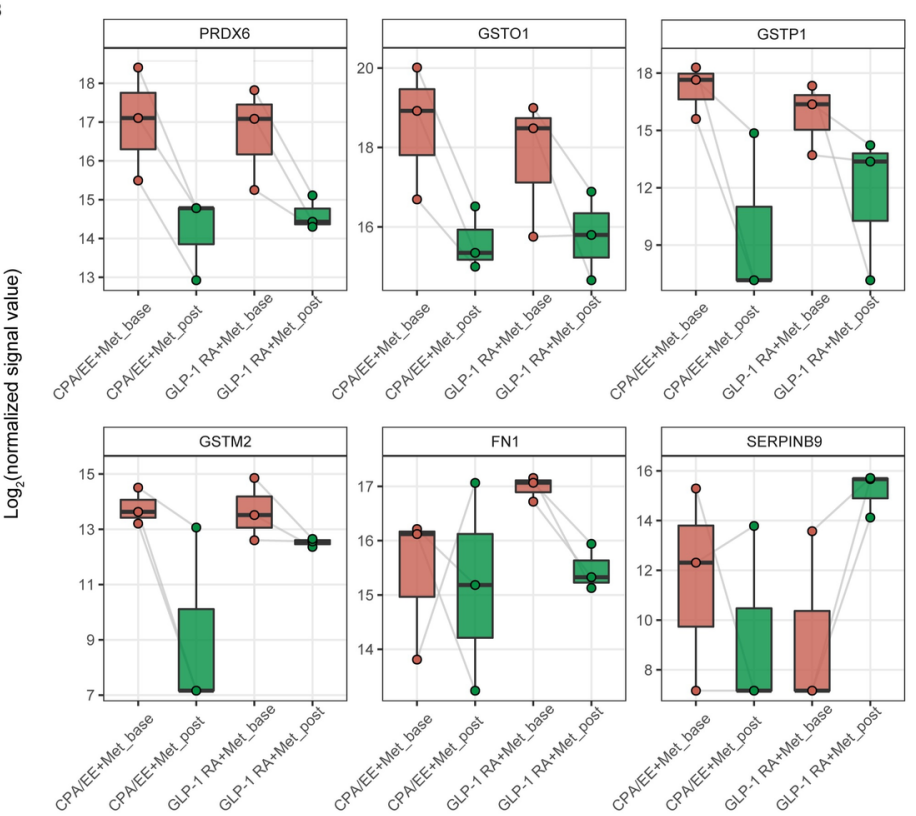

